\title{
Nódulos Reumatóides Pulmonares Precedendo o Aparecimento de Artrite
}

\section{Pulmonary Rheumatoid Nodules Preceding Arthritis Development}

\author{
José Eduardo Martinez ${ }^{(1)}$, José Antonio Gianini ${ }^{(2)}$, Maria Cecília Ferro $^{(3)}$, Fábio Nishida Hasimoto ${ }^{(4)}$, \\ Hélio Kiyoshi Hasimoto $^{(5)}$, Sérgio Penteado de Oliveira Júnior ${ }^{(6)}$
}

\section{RESUMO}

A artrite reumatóide é uma doença sistêmica, de causa desconhecida e de natureza auto-imune. A característica clínica principal é a poliartrite crônica, em geral envolvendo pequenas e grandes articulações, com tendência a deformidades e incapacidades. A presença de nódulos subcutâneos pode ser parte da apresentação clínica e tem histopatologia típica. O comprometimento visceral pode incluir os pulmões, vasos, pericárdio etc. O envolvimento pulmonar pode se apresentar com derrame pleural, bronquiolite, vasculite pulmonar e mais raramente nódulos reumatóides. O desenvolvimento clássico é o dos envolvimentos viscerais após o aparecimento da artrite. Os nódulos reumatóides pulmonares têm baixa prevalência. Seu desenvolvimento precedendo a artrite acrescenta interesse ao assunto. Relata-se um caso de paciente do sexo feminino com nodulose reumatóide pulmonar que precedeu o envolvimento articular.

Palavras-chave: artrite reumatóide, nódulos reumatóides, pneumopatia.

\section{INTRODUÇÃO}

A artrite reumatóide é uma doença sistêmica de natureza auto-imune caracterizada por inflamação articular crônica com potencial para o desenvolvimento de deformidades e incapacidade funcional. $\mathrm{O}$ diagnóstico realiza-se por uma combinação de quadro clínico, laboratorial e radiológico, levando-se em conta tanto a apresentação inicial quanto a evolução característica. O diagnóstico precoce é extremamente importante porque o desenvolvimento de erosões ósseas subcondrais ocorre com maior velocidade nos primeiros anos de doença ${ }^{(1)}$.

\begin{abstract}
Rheumatoid arthritis is a systemic disease of unknown cause and autoimune disease mechanisms. Its main clinical feature is a chronic polyarthritis involving large and small joints that may cause deformities and disabilities. Subcutaneous nodules can be part of the clinical presentation with a typical pathological appearance. Visceral involvement may include lungs, pericardium, and blood vessels. Pulmonary involvement is characterized by pleural effusions, vasculitis, bronchiolitis and pulmonary rheumatoid nodules. Usually, visceral manifestations appear after arthritis development. Pulmonary rheumatoid nodules are a rare feature. Its development preceding arthritis make this characteristic even more interesting. Our case report refers to a female patient with pulmonary rheumatoid nodules that has preceded the arthritis.
\end{abstract}

Keywords: rheumatoid arthritis, rheumatoid nodules, lung disease.

Embora a atenção maior seja dispensada às manifestações osteoarticulares, a doença reumatóide é uma doença auto-imune sistêmica. O caráter generalizado dessa enfermidade se estabelece pelo envolvimento visceral que pode acompanhar a artrite. Geralmente as manifestações extraarticulares associam-se aos altos títulos de fator reumatóide sérico e a pior prognóstico articular. Entre esses achados, podem-se citar o comprometimento do tecido celular subcutâneo (nódulos reumatóides), pulmonar, cardíaco, vascular e o risco aumentado de infecções ${ }^{(1,2)}$.

\footnotetext{
Recebido em 8/4/2007. Aprovado, após revisão, em 22/11/2007. Declaramos a inexistência de conflitos de interesse

Pontifícia Universidade Católica de São Paulo.

1. Professor titular do Departamento de Medicina

2. Cirurgião de tórax do Hospital Santa Lucinda, Pontifícia Universidade Católica de São Paulo (PUC-SP).

3. Professora titular do Departamento de Morfologia e Patologia.

4. Acadêmico de medicina

5. Cirurgião de tórax do Hospital Santa Lucinda, PUC-SP.

6. Cirurgião de tórax do Hospital Santa Lucinda, PUC-SP.

Endereço para correspondência: Centro de Ciências Médicas e Biológicas de Sorocaba, Praça José Ermírio de Moraes, 290, CEP 18030-230, Sorocaba, SP, e-mail: jemartinez@terra.com.br
} 
Em relação aos nódulos reumatóides, eles em geral se localizam predominantemente nas faces extensoras das articulações. Sua observação tem importância clínica, tanto no diagnóstico quanto no estadiamento. Raramente, podem apresentar-se sem a presença de artrite, caracterizando a nodulose reumatóide. A histologia característica é da presença de necrose fibrinóide circundada por células mononucleares em paliçada envolvida por linfócitos e células plasmáticas $^{(2)}$.

O envolvimento pulmonar chama particularmente a atenção por sua freqüência e potencial morbidade. Sessenta e nove por cento de pacientes sintomáticos e $20 \%$ de assintomáticos têm anormalidades pulmonares detectadas por intermédio de tomografia computadorizada de alta resolução ${ }^{(3)}$. Quanto à mortalidade, as manifestações pulmonares são consideradas a segunda causa de morte após infecções, atingindo 18\% dos óbitos. Entre elas, podemos citar: derrame pleural, fibrose intersticial, vasculite e nódulos reumatóides ${ }^{(4)}$.

O interesse no caso ora relatado refere-se ao desenvolvimento de doença reumatóide pulmonar caracterizado por nódulos sem alterações articulares. A paciente apresentou poliartrite após intervenção cirúrgica para tratamento e diagnóstico de nódulos pulmonares que se mostraram, do ponto de vista anatomopatológico, compatíveis com nódulo reumatóide. Nódulos reumatóides pulmonares como manifestação inicial de artrite reumatóide é um evento raro e de interesse científico, já que deve ser considerado no diagnóstico diferencial das neoplasias benignas pulmonares.

\section{RELATO DE CASO}

Identificação: VCO, 45 anos, casada, dona de casa, branca, sexo feminino, natural e procedente de Sorocaba, SP.

Queixa de duração: Dispnéia aos médios esforços e crises de dor torácica há quatro anos.

História clínica: A paciente refere ter apresentado episódios de "pneumonia" há quatro anos, caracterizados por tosse com expectoração esbranquiçada e dispnéia de moderada intensidade. Nessas ocasiões apresentava dor em hemitórax esquerdo, ventilatório-dependente. Nos intervalos entre as "pneumonias" e até o momento vem apresentando dispnéia aos esforços e períodos de dor ao esforço localizada em ambas as bases torácicas. No final de 2004, procurou pneumologista que constatou, por meio de exame físico e exames de imagem, nódulos pulmonares bilateralmente. Foi indicada cirurgia, e o material obtido por intermédio da biópsia foi submetido ao exame anato- mopatológico que constatou quadro histológico compatível com nódulo reumatóide e bronquiolite folicular. Até então a paciente não apresentava queixas articulares. Foi encaminhada ao reumatologista para investigação.

Comprometimento articular: Aproximadamente três meses após a cirurgia torácica, a paciente desenvolveu poliartrite, caracterizada por artralgias de pequenas e grandes articulações (mãos, punhos, ombros e joelhos), acompanhada de rigidez matinal por cerca de quatro horas.

Exames laboratoriais de interesse: Hemograma normal, eletroforese de proteínas com hipergamaglobulinemia $(1,68 \mathrm{mg} / \mathrm{dL})$, velocidade de hemossedimentação de $54 \mathrm{~mm} / \mathrm{l}^{\text {ahora, }}$ fator reumatóide positivo pela prova do Látex (118 UI) e FAN positivo 1/160 pontilhado por IFI no diagnóstico do quadro pulmonar. Por ocasião da instalação do quadro articular, o hemograma permaneceu normal, a hemossedimentação na primeira hora passou a $68 \mathrm{~mm}$, o fator reumatóide passou a 320 UI e o FAN com padrão pontilhado fino apresentou título de 1/640 (Tabela 1).

TABELA 1

VALORES DOS EXAMES IMUNOLÓGICOS ANTES E DEPOIS DO DESENVOLVIMENTO DA ARTRITE

\begin{tabular}{lcc}
\hline EXAMES & PRÉ-ARTRITE & PÓS-ARTRITE \\
\hline Hemossedimentação/Primeira hora & $54 \mathrm{~mm}$ & $68 \mathrm{~mm}$ \\
Fator reumatóide & $118 \mathrm{UI}$ & $320 \mathrm{UI}$ \\
Fator antinúcleo & $1 / 160$ & $1 / 640$ \\
\hline
\end{tabular}

Exame radiográfico do tórax: Apresenta áreas de aumento da densidade do parênquima, de limites imprecisos em lobo inferior esquerdo e velamento de seio costofrênico esquerdo (Figura 1).

Tomografia computadorizada de tórax: Presença de cistos amorfos, com paredes levemente espessadas e com discreto predomínio em campos pulmonares médios. Observam-se também nódulos em todos os lobos pulmonares, o maior medindo $1,5 \mathrm{~cm}$. Dois desses nódulos são subpleurais e apresentam calcificações em seu interior (Figura 2).

\section{ANATOMOPATOLÓGICO DO MATERIAL OBTIDO NA BIÓPSIA (FIGURA 3)}

Macroscopia: Segmento de pulmão com $13 \mathrm{~cm} \mathrm{x}$ $2,8 \mathrm{~cm} \times 2 \mathrm{~cm}$ com dois nódulos esbranquiçados, densos, medindo o maior $1,2 \mathrm{~cm} \times 1,0 \mathrm{~cm} \times 0,8 \mathrm{~cm}$; raras áreas císticas medindo $0,2 \mathrm{~cm}$. 


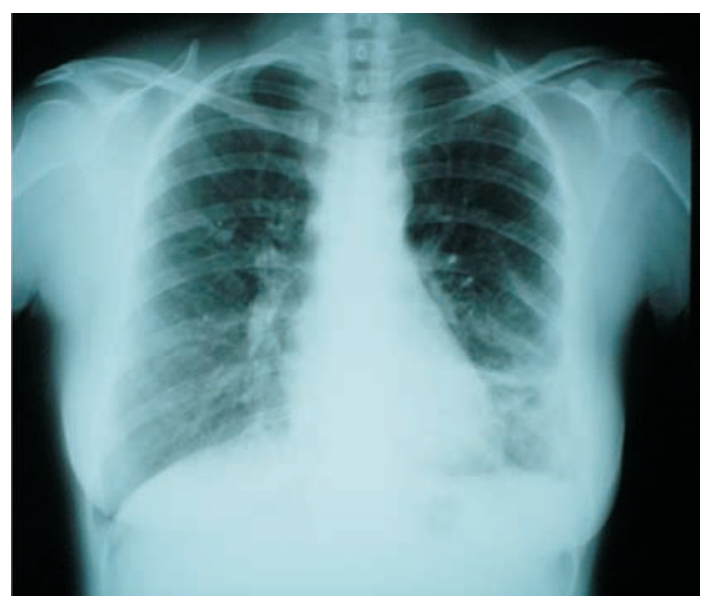

Figura 1 - Radiografia simples de tórax com áreas de aumento da densidade do parênquima, de limites imprecisos em lobo inferior esquerdo e velamento de seio costo-frênico esquerdo.

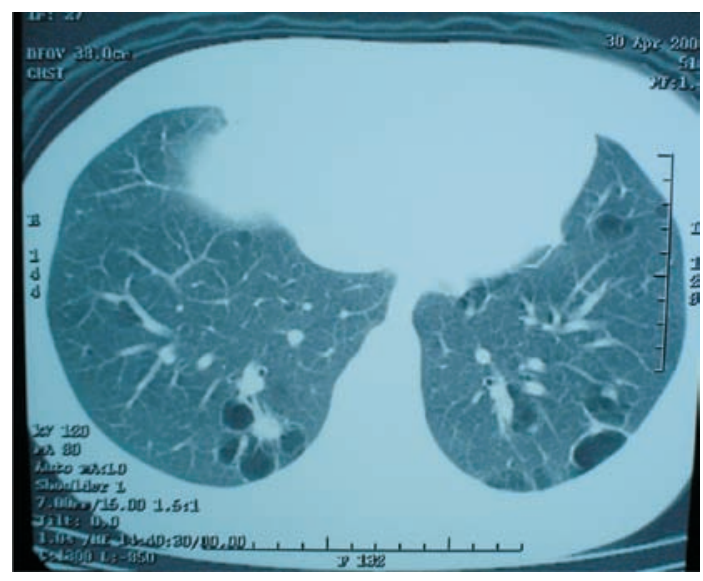

Figura 2 - Corte tomográfico mostrando nódulos no parênquima pulmonar.

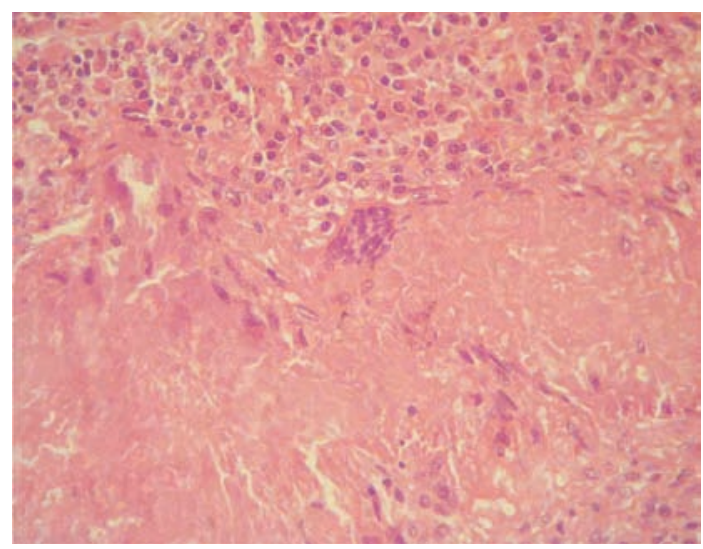

Figura 3 - Processo inflamatório com linfócitos, reação de células gigantes multinucleadas, área central com necrose.
Microscopia: Tecido pulmonar com infiltrado linfohistiocítico em paliçada esboçando arranjo granulomatoso; em torno material eosinofílico, com células gigantes multinucleadas do tipo corpo estranho e plasmócitos. O processo compromete as adjacências do eixo broncovascular, às vezes formando cavidades. Nos bronquíolos há acúmulo linfóide com arranjo folicular e no parênquima pulmonar há áreas de hemorragia e colapso, além de macrófagos contendo hemossiderina. As pesquisas de material amilóide e a coloração para BAAR foram negativas. Conclusão: Processo inflamatório granulomatoso pulmonar em torno de nódulos reumatóides, associado à bronquiolite folicular.

Tratamento e evolução: A paciente foi submetida a corticosteróide em dose baixa e metotrexato, 7,5 mg/semana. Desenvolveu urticária após a terceira dose de metotrexato, sendo, então, substituído por hidroxicloroquina, $400 \mathrm{mg}$ / dia. Houve melhora de dor articular, edema e rigidez matinal após dois meses de uso. Mantém, porém, dispnéia aos grandes esforços e dor torácica ocasional.

\section{DISCUSSÃO}

O acometimento pulmonar na doença reumatóide apresenta-se mais freqüentemente por meio de envolvimento pleural, fibrose intersticial, bronquiolite obliterante e nódulo reumatóide. Embora a artrite reumatóide seja mais comum em mulheres, o envolvimento pulmonar é mais comum em homens, com doença de longa data, com fator reumatóide positivo e com nódulos subcutâneos.

Cerca de $20 \%$ dos pacientes têm sintomas de origem pleural, embora a freqüência de pleurite em necrópsias seja bem mais elevada ( $40 \%$ a $75 \%)$. O derrame pleural, em geral, associa-se à atividade inflamatória articular e raramente pode precedê-la. Muitas vezes a pleurite é assintomática e pode ocorrer concomitantemente com a fibrose intersticial e a bronquiolite obliterante ${ }^{(1,3)}$.

A fibrose intersticial ocorre em $1 \%$ a $5 \%$ dos pacientes quando diagnosticada pela radiografia simples. Já por intermédio de provas ventilatórias pode-se chegar a uma prevalência de $40 \%$, com padrão restritivo. Esse achado clínico é precedido por artrite em $90 \%$ dos casos, e é mais comum em homens entre 50 e 60 anos e com fator reumatóide positivo. Seu comportamento é semelhante ao da fibrose intersticial idiopática ${ }^{(1,3,4)}$.

A bronquiolite obliterante é precedida por um quadro semelhante à infecção viral, tem natureza aguda, com duração em geral menor que três meses. Caracteriza-se por tosse, dispnéia e outros sintomas respiratórios inespecíficos. 
Radiologicamente, observa-se hiperinsuflação e, menos freqüentemente, áreas de fibrose localizada ${ }^{(3)}$. No caso ora relatado, constatou-se bronquiolite no anatomopatológico em associação com nódulos pulmonares. A bronquiolite caracterizou-se por acúmulo linfóide nos bronquíolos formando um arranjo folicular.

O aspecto de interesse nesse caso é a presença de nódulos no pulmão na ausência do diagnóstico de artrite reumatóide. Os nódulos pulmonares geralmente se localizam na periferia dos lobos médios ou superiores, podendo ser únicos ou múltiplos. Eles caracterizam-se por área central de necrose fibrinóide, envolvida por uma camada de células mononucleares em paliçada entre uma zona vascular de tecido de granulação, plasmócitos e fibroblastos ${ }^{(1,2,5,6)}$. O quadro histopatológico desse caso não apresenta a conformação típica, podendo, entretanto, observarem-se a necrose fibrinóide, as células mononucleares em paliçada (não envolvem totalmente a área de necrose), os plasmócitos e os fibroblastos na periferia.

A etiopatogenia é desconhecida, mas acredita-se que haja envolvimento de vasculite causada por deposição de imunocomplexos ${ }^{(5,6,7)}$.

Os nódulos pulmonares são encontrados geralmente em pacientes com nódulos também no subcutâneo e fator reumatóide positivo. Geralmente são identificados em menos de $1 \%$ das radiografias de pacientes ${ }^{(5,6,7)}$.

Neste caso, a hipótese diagnóstica de $\mathrm{AR}$ não foi formulada porque inicialmente a paciente não referia queixas articulares e não apresentava provas de atividade

\section{REFERÊNCIAS}

1. Anaya JM, Diethelm L, Ortiz LA, et al.: Pulmonary involvement in rheumatoid artritis. Seminars Arthritis Rheum 24(4): 242-54,1995.

2. Kaye BR, Kaye R, Brovove A: Rheumatoid nodules. Review of the spectrum of associated conditions and proposal of a new classification with a report of four seronegative cases. Am J Med 76(2): 279-82, 1984

3. Perez T, Wallaert B, Tonnel AB: Pleuropulmonary manifestations of rheumatoid arthritis. Rev Mal Resp 8(2): 169-89, 1991.

4. Cortet B, Flipo RM, Remy-Jardin M, Delcambre B: Use of high resolution computed tomography of the lungs in patients with rheumatoid artritis. Ann Rheum Dis 54(10): 815-9, 1995.

5. Ziff M: The rheumatoid nodules. Arthritis Rheum 33(3): 731-66, 1990.

6. Scadding JG: The lungs in rheumatoid arthritis. Proc R Soc Med 62: $227-38,1969$. inflamatória alteradas. Chama atenção o desenvolvimento de poliartrite crônica, compatível com AR, após a toracotomia, preenchendo, então, os critérios para o diagnóstico definitivo. Portanto, o aspecto marcante deste caso e que resultou esta publicação foi a raridade na literatura da nodulose pulmonar como manifestação inicial de AR. Geralmente as manifestações pulmonares ocorrem na evolução dos casos mais severos de AR e com a presença de fator reumatóide positivo.

A literatura médica descreve raros casos com a apresentação clínica inicial com nódulos pulmonares, e a revisão bibliográfica revelou apenas nove casos nos quais o intervalo entre o diagnóstico dos nódulos pulmonares e o surgimento da artrite variou de poucas semanas a $19 \operatorname{anos}^{(7-11)}$. Na paciente deste relato o intervalo entre o início das manifestações e o desenvolvimento de artrite foi de quatro anos, mas entre o diagnóstico dos nódulos e a artrite foi de apenas três meses.

A importância dessas descrições também refere-se ao diagnóstico diferencial entre os nódulos reumatóides e a presença de neoplasia pulmonar, primária ou metastática. O diagnóstico definitivo, em geral, só ocorre após biópsia pulmonar, mesmo nos casos com doença reumatóide já diagnosticada $^{(11,12)}$.

Conclui-se, portanto, que as manifestações pulmonares da artrite reumatóide podem preceder o quadro articular e devem ser consideradas no diagnóstico diferencial dos nódulos pulmonares.

7. Laloux L, Chevalier X, Maitre B, Lange F, Chanzy BL, Claudepierre P: Unusual onset of rheumatoid arthritis with diffuse pulmonary nodulosis: a diagnostic problem. J Rheumatol 26(4): 920-2, 1999.

8. Eraut CD, Evans JA, Caplin M: Pulmonary necrobiotic nodules without rheumatoid arthritis. Br J Dis Chest 72: 301-6, 1978.

9. Nusslein HG, Rodl W, Giedel J, Missmahl M, Kalden JR Multiple peripheral pulmonary nodules preceding rheumatoid arthritis. Rheumatol Int 7: 89-91, 1987.

10. Hull S, Mathews JA: Pulmonary necrobiotic nodules as a presenting feature of rheumatoid arthritis. Ann Rheum Dis 41: 21-4, 1982.

11. Voulgari PV, Tsifetak N, Metafrazi XM, Zioga A, Acritidis NC, Drosos AA: A single pulmonary rheumatoid nodule masquerading as malignancy. Clin Rheumatol 24: 556-9, 2005.

12. Hanada T, Hizawa N, Ogura $S$, et al.: A necrobiotic nodule indistinguishable from lung andocarcinoma. Nihon Kyoubu Shikkan Gakkai Zasshi 33: 369-72, 1995. 